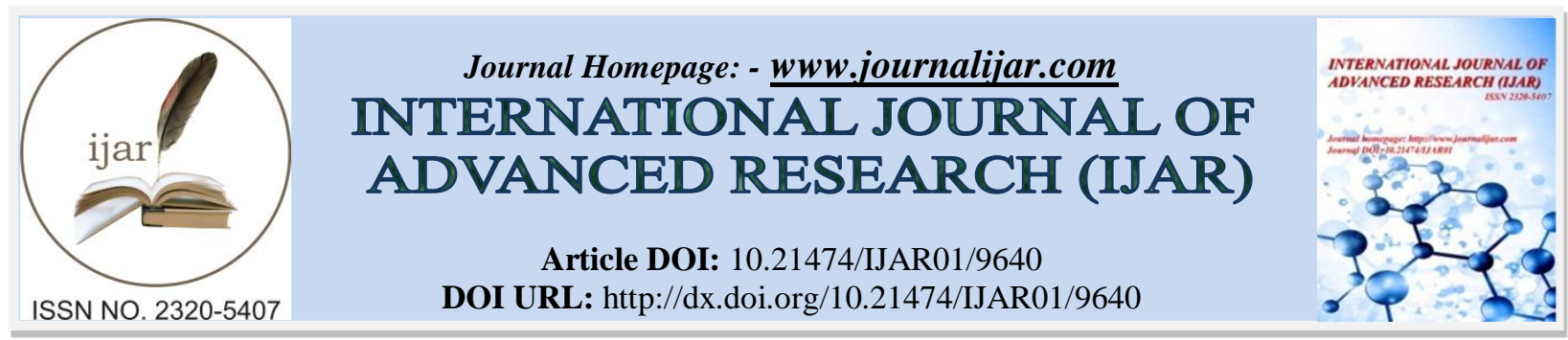

RESEARCH ARTICLE

\title{
THE EFFECT OF REPEATED TEMPERATURE VARIATIONS AND FREEZE THAW PHENOMENON ON SOME DURABILITY ASPECTS OF CONCRETE.
}

\author{
K. Lagrini ${ }^{1}$, A.Ghafiri ${ }^{1}$, A.Ouali ${ }^{2}$ and S.Moutaki ${ }^{1}$.
}

1. Laboratory of Applied Geology, Geomatics and Environment Hassan II University of Casablanca, Faculty of Sciences Ben M'sik, Av Driss El Harti, Sidi Othmane Casablanca B.P 7955, Morocco.

2. Laboratory for Studies and Experiments, Km 7 Road of El Jadida, Casablanca, Morocco.

\section{Manuscript Info}

Manuscript History

Received: 02 July 2019

Final Accepted: 04 August 2019

Published: September 2019

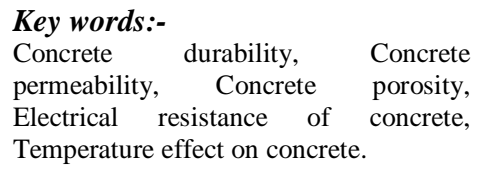

Key words:-

Concrete

Electrical resistance of concrete,

Temperature effect on concrete.

\begin{abstract}
The degradation of reinforced concrete structures is the result of numerous attacks due to the environment in which they live, which threatens the durability of this concrete. Among the parameters that affect the durability of concrete is the change in outdoor temperature, between day and night, summer and winter. This paper reflects the experimental work carried in order to better understand the effect of temperature variations on some durability aspects of an ordinary concrete frequently used in Morocco for bridges. To do this, samples of concrete were made, according to an ordinary formulation, to realize in the laboratory a program of tests which allowed us to determine the values of some durability parameters such as the porosity to water, the gas permeability, the electrical resistance and the chloride ion diffusion coefficient. The simulation of this variation in the laboratory is accelerated thanks to a temperature-controlled chamber according to 6 hours long cycle which is repeated and which varies in the range -5 to $40^{\circ} \mathrm{C}$ reflecting the Moroccan climate. Although 300 temperature variation cycles have relatively little effect on standard concrete, results show that the shrinkage has begun only after 50 cycles along with a significant loss of mass. Also, its permeability has increased due to the repetitive temperature variations.
\end{abstract}

Copy Right, IJAR, 2019,. All rights reserved.

\section{Introduction:-}

Concrete is a material that is more and more used in civil engineering structures thanks to its safety and aestheticrelated advantages. In fact, over three tons of concrete are produced each year per person for the entire global population, making it the most widely used manufactured product in the world (International Finance Corporation, 2014). However, this material is likely to undergo several types of degradation due to the applied loads and/or the structure's environment. The intrinsic durability of concrete alone is no longer sufficient to guarantee the service life of the structure. The durability directly related to the immediate or future environment of the structure and part of the structure is now considered to be the important parameter to be taken into account in order to optimize the resistance of concrete to external factors: bad weather, soil aggression, chemically aggressive atmospheres. Therefore, establishing a durable concrete requires a preliminarily assessment of all environmental conditions, aggressions and potential attacks that the concrete is likely to undergo throughout its service life and to abide by the dispositions of the standards.

Corresponding Author:-K. Lagrini.

Address:-Laboratory of Applied Geology, Geomatics and Environment Hassan II University of 
One of the most important parameters of the environment that have remarkable impacts on concrete is air temperature. In fact, understanding the behaviour of this material with regard to ambient temperature will allow us to suggest suitable solutions to improve its durability. This is of a very big economic, security and environmental interest. On one hand, increasing the durability of a concrete structure like a dam, a bridge, a road or a building will save thousands of dollars that would have been spent for the rehabilitation of this work over the years or for the construction of a new structure in the case of rupture. Hence, getting to know the behaviour of a certain type of concrete when subjected to numerous types of degradation is the only solution to reduce the economic costs of rehabilitation or reconstruction. On the other hand, the effects of temperature increase over time can lead to the acceleration of a number of degradations, which can cause the rupture of the structure putting the safety of individuals in danger. Furthermore, the cement manufacturing industry is one of the main contributors to industrial $\mathrm{CO} 2$ emissions following power industry, which account for 5\% to $7 \%$ of global anthropogenic $\mathrm{CO} 2$ emissions (Cheng-Yao Zhang, 2018) and has a significant environmental footprint due to the extensive amounts of energy and raw materials used in the process (International Finance Corporation, 2014). Furthermore, more than 4 billion tonnes of cement are produced each year, accounting for around 8 per cent of global CO2 emissions (Preston, 2018). Moreover, the rupture of a structure such as a bridge, a dam or a building can have a disastrous effect on the environment, which can only be avoided through a better knowledge of the behaviour of this material subjected to external conditions. Thus, increasing the durability of a structure through prior knowledge of the effects of environmental conditions can reduce the need to produce large quantities of cement and reduce the emission of greenhouse gases, which is a common motivation of countries in the framework of the United Nations Convention on Climate Change. Morocco accords a special interest to this issue and is carrying out actions reflecting the political goodwill to respect its national and international commitments with regards to the environment and sustainable development.

Recent studies have shown the existence of a causal relationship between the variation of the ambient temperature in which the concrete is located and its durability. For example, (Jianda Xin, 2018) found that the magnitude of cracking potential of an early age concrete varies significantly under different temperature histories and (Moad Isteita, 2017) found that temperature variation significantly increases the chloride penetration process when the temperature amplitude and the gradient of chloride are in the same direction. (Gallucci, 2006) found that the compressive strength of concrete is strongly influenced by ambient temperature. He states that after one year and for the same concrete, the compressive strength for a sample placed in temperatures of 5 or $20^{\circ} \mathrm{C}$ is of the order of 50 $\mathrm{MPa}$, the one placed at $40^{\circ} \mathrm{C}$ is $43 \mathrm{MPa}$ and at $60^{\circ} \mathrm{C}$ is $35 \mathrm{MPa}$. However, very little work has been done to determine the behaviour of a commonly used concrete when subjected to ambient temperature variations adapted to the case of some Mediterranean or African countries such as Morocco. This paper describes the evolution of some of the durability indicators such as the porosity to water, the gas permeability, the electrical resistance and the chloride ion diffusion coefficient, of a concrete subjected to temperature cycles ranging from- $-{ }^{\circ} \mathrm{C}$ to $40{ }^{\circ} \mathrm{C}$, which is consistent with the Moroccan climate conditions.

\section{Methods and materials:- Thermal cycle}

The methodology followed consists in subjecting 28-day concrete specimens to accelerated temperature cycles using a temperature-controlled chamber in accordance with the method described in the American Standard (ASTM C666 , 2015) and the French standards P18-424 (AFNOR, 1994) and P18-425 (AFNOR, 1994). Durability tests are then carried out and pursued up to 300 cycles on the various test specimens according to the same standards mentioned above. To do this and although more recent standards exist, we have chosen to get inspired by the French standards P18-424 (AFNOR, 1994) and P18-425 (AFNOR, 1994) in order to define a temperature cycle that reflects the Moroccan climatic conditions, to be able to determine the impact of temperature changes present at national level on some indicators of concrete durability.

In fact, some studies have been carried out in order to characterize the Moroccan climate (Lagrini K., 2016). According to these studies and to direct consultation with the Direction of National Meteorology, Morocco's peak temperatures can go down to $-5{ }^{\circ} \mathrm{c}$ and they can reach $+40{ }^{\circ} \mathrm{c}$. It is therefore these critical temperatures that are considered to be the most unfavorable and that we have chosen to define the temperature cycle for a duration of 6 hours as per the dispositions of the P18-424 standard (AFNOR, 1994).

Number and Size of the test specimens 
The number and size of the test specimens are dictated by the number of tests and their destructive character. In fact, the durability indicators for the gas permeability test, water-accessible porosity, chloride ion migration and electrical resistivity are calculated for 28 days-hardened concrete after 50 cycles, 100 cycles, 200 cycles and 300 cycles. In addition, sample specimens are also made and the same tests are carried out after 28 days, 56 days and 90 days.

Thus, the number of test pieces required is as follows:

Table 1:-Number and size of test specimens

\begin{tabular}{|l|l|l|l|}
\hline Test & Dimensions & Number of specimens & Standards of tests \\
\hline Gas permeability test & $\begin{array}{l}\text { cylindrical specimens of } \\
15 * 30\end{array}$ & $\begin{array}{l}\text { XP P18-463 (AFNOR, } \\
2011)\end{array}$ \\
\hline $\begin{array}{l}\text { Water-accessible porosity } \\
\text { tests }\end{array}$ & $\begin{array}{l}\text { cylindrical test specimens } \\
\text { of } 10 * 22\end{array}$ & 7 & $\begin{array}{l}\text { NF P18-459 } \\
\text { 2010) }\end{array}$ \\
\hline $\begin{array}{l}\text { Test for the migration of } \\
\text { chloride ions }\end{array}$ & $\begin{array}{l}\text { cylindrical test specimens } \\
\text { of } 10 * 22\end{array}$ & $\begin{array}{l}\text { NT } \\
\text { (NTBUILD-492, 1999) }\end{array}$ \\
\hline Electrical resistivity test & $\begin{array}{l}\text { cylindrical test specimens } \\
\text { of } 10 * 22\end{array}$ & $\begin{array}{l}\text { ASTM G57-06 (ASTM, } \\
\text { 2012) }\end{array}$ \\
\hline
\end{tabular}

\section{Preparation of test specimens}

We have adopted a concrete resistance class C40/55, as described in the Table 2, recommended for structures with a 100-year service life in Morocco.

Table 2:-Formulation of the concrete used to prepare the test specimens

\begin{tabular}{|l|l|}
\hline \multicolumn{1}{|c|}{ Component } & Proportion en $\mathrm{Kg} / \mathrm{m} 3$ \\
\hline Gravette G1 (8/15) $(\mathrm{Kg} / \mathrm{m} 3)$ & 980 \\
\hline Sand dune Azemmour $(\mathrm{Kg} / \mathrm{m} 3)$ & 320 \\
\hline Pound sand (Kg/m3) & 600 \\
\hline Cement CPJ55 (ASMENTTEMARA) $(\mathrm{Kg} / \mathrm{m} 3)$ & 380 \\
\hline water $(\mathrm{Kg} / \mathrm{m} 3)$ & 164 \\
\hline Admixture (Glenium $118 \mathrm{BASF})(\mathrm{Kg} / \mathrm{m} 3)$ & 5,7 \\
\hline
\end{tabular}

Since the mixer only allows us to mix 70L of concrete each time, and due to the limited number of moulds and studs, we had to repeat the process twice in order to prepare all the specimens we need according to the compositions and characteristics described in Tables 3 and 4.

Table 3:-Composition of the two mixtures With

\begin{tabular}{|l|l|l|l|l|l|l|}
\hline & \multicolumn{2}{|l|}{ Water content, \% } & Dry mass, Kg & Wet mass \\
\hline & Mixture 1 & Mixture 2 & Mixture 1 & Mixture 2 & Mixture 1 & Mixture 2 \\
\hline Gravette G1 & 0,5 & 0,5 & 68,60 & 38,22 & 68,94 & 38,41 \\
\hline Sand dune Azemmour & 8,6 & 0,42 & 22,40 & 12,48 & 24,33 & 12,53 \\
\hline Pound sand CPJ55 & 3,7 & 0,8 & 42,00 & 23,40 & 43,55 & 23,59 \\
\hline $\begin{array}{l}\text { Cement } \\
\text { (ASMENTTEMARA) }\end{array}$ & & 26,60 & 14,82 & 26,60 & 14,82 \\
\hline water & & & 11,48 & 6,40 & 7,66 & 5,97 \\
\hline $\begin{array}{l}\text { Admixture (Glenium 118 } \\
\text { BASF) }\end{array}$ & & 0,399 & 0,2223 & 0,399 & 0,2223 \\
\hline
\end{tabular}

Table 4:-characteristics of the two mixtures

\begin{tabular}{|l|l|l|}
\hline & Mixture 1 & Mixture 2 \\
\hline Total volume, L & 70 & 39 \\
\hline Concrete Temperature, ${ }^{\circ} \mathrm{C}$ & 19 & 19,7 \\
\hline Ambiant T, ${ }^{\circ} \mathrm{C}$ & 17 & 20 \\
\hline Slamp, cm & 20 & 22 \\
\hline
\end{tabular}

\section{Conservation conditions}


Initially, all the test specimens were preserved in the same way. After casting, the test specimens were kept for 24 hours in the temperature and humidity conditions of the room. At the end of this initial storage time, they were demoulded and numbered and then plunged into water at $20^{\circ} \mathrm{c}$. This type of conservation is most favorable to the process of hydration of cement. Then, a detailed schedule of the tests was established and the test specimens underwent different treatments according to two categories:

1. After 28 days of storage in water at $20^{\circ} \mathrm{c}, 4$ specimens of $15 * 30,12$ test specimens of $10 * 22$ were put in the temperature-controlled chamber to undergo the cycles of variation of temperature.

2. After 28 days of storage in water at $20{ }^{\circ} \mathrm{c}, 3$ specimens of $15 * 30$ and 9 test specimens of $10 * 22$ were stored at room temperature and served as control specimens.

\section{Results And Discussion:-}

1. The porosity's values are between 12 and 14 , so the potential durability of our concrete remains average throughout according to (AFGC, 2004). It is noted that the porosity value does not vary greatly, either for the sample specimens or for those that have undergone the temperature variation cycles. We notice a slight decrease for the sample specimens from 14 to 12 . This could be explained by the fact that the cement grains continue to hydrate and fill the pores hence the decrease in porosity. As for the test specimens that have undergone the temperature cycles, the porosity decreases to a value of 12 at the 100th cycle. Then it starts to increase. This increase is not very significant but can be explained by the fact that the free water contained in the pores undergoes freeze-thaw cycles, which creates micro cracks in the concrete thus increasing its porosity.

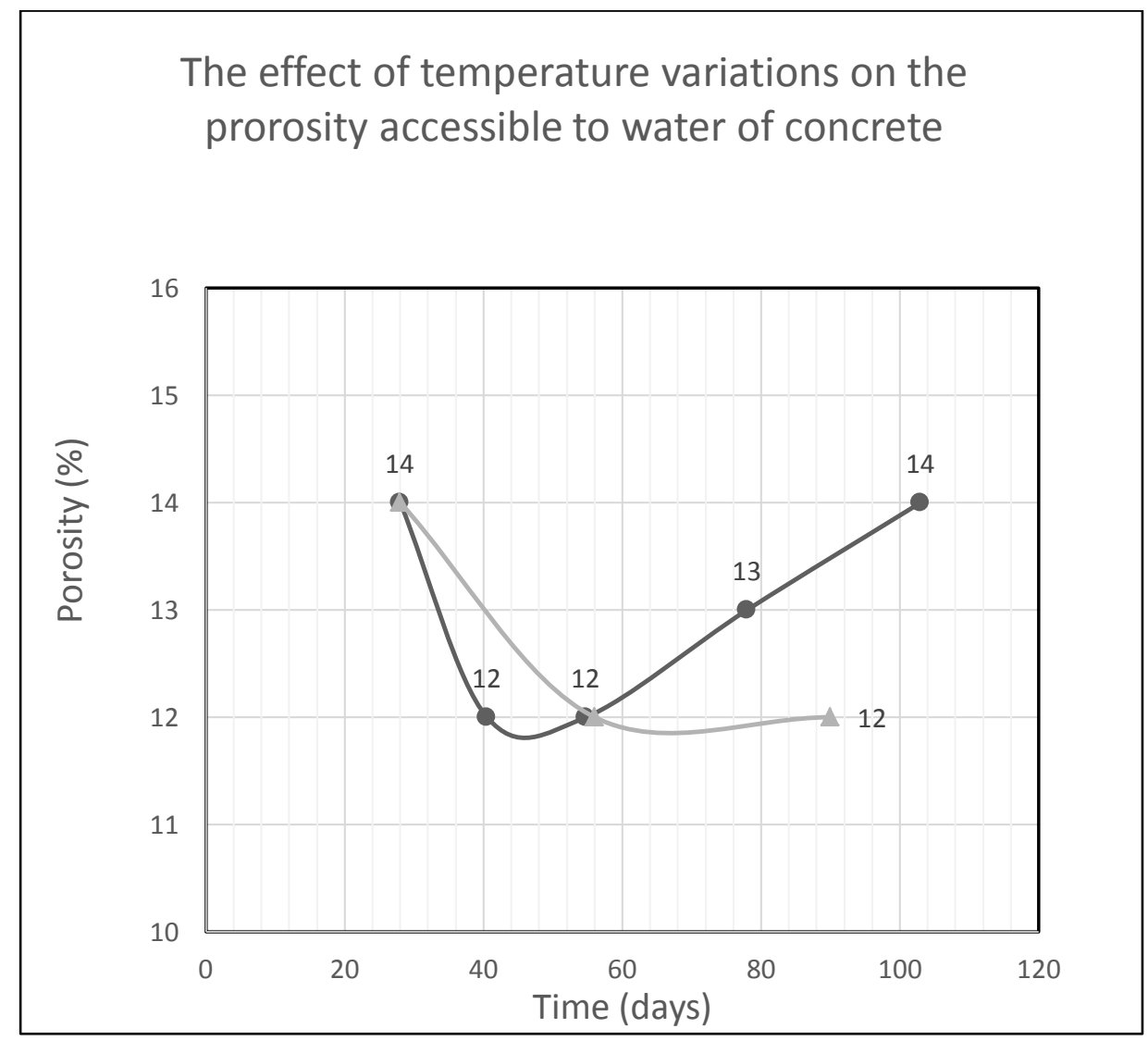

Figure 1:-The evolution of porosity accessible to water with: the graph in black represents the evolution of porosity for test specimens having undergone temperature variation cycles and the graph in grey represents sample specimens.

2. The values of electrical resistivity are between 50 and 100 , so the potential durability of the concrete remains low according to (AFGC, 2004) either for the sample specimens or for those which have undergone the temperature variation cycles. It is noted that the electrical resistivity increases over time for sample specimens, which is expected since durability characteristics improve during the first 90 days. For test specimens which 
have undergone the temperature cycles, the electrical resistivity increases and reaches its maximum value at 50 cycles and then decreases and reaches a minimum value of 62.5 at 200 cycles. The increase in resistance, during the time corresponding to the first 50 cycles, for the sample specimens, is more important than that of the test specimens which have undergone the cycles. The effect of temperature cycles on the test specimens can be seen in the first 28 days, but the effect is heightened and is clearly visible after 50 cycles, the graph completely changes its monotony. This could be explained by the fact that the temperature variation impacts the chemistry of the pore water and that the freeze-thaw phenomenon contributes to the appearance of micro cracks which implies the reduction of the electrical resistivity.

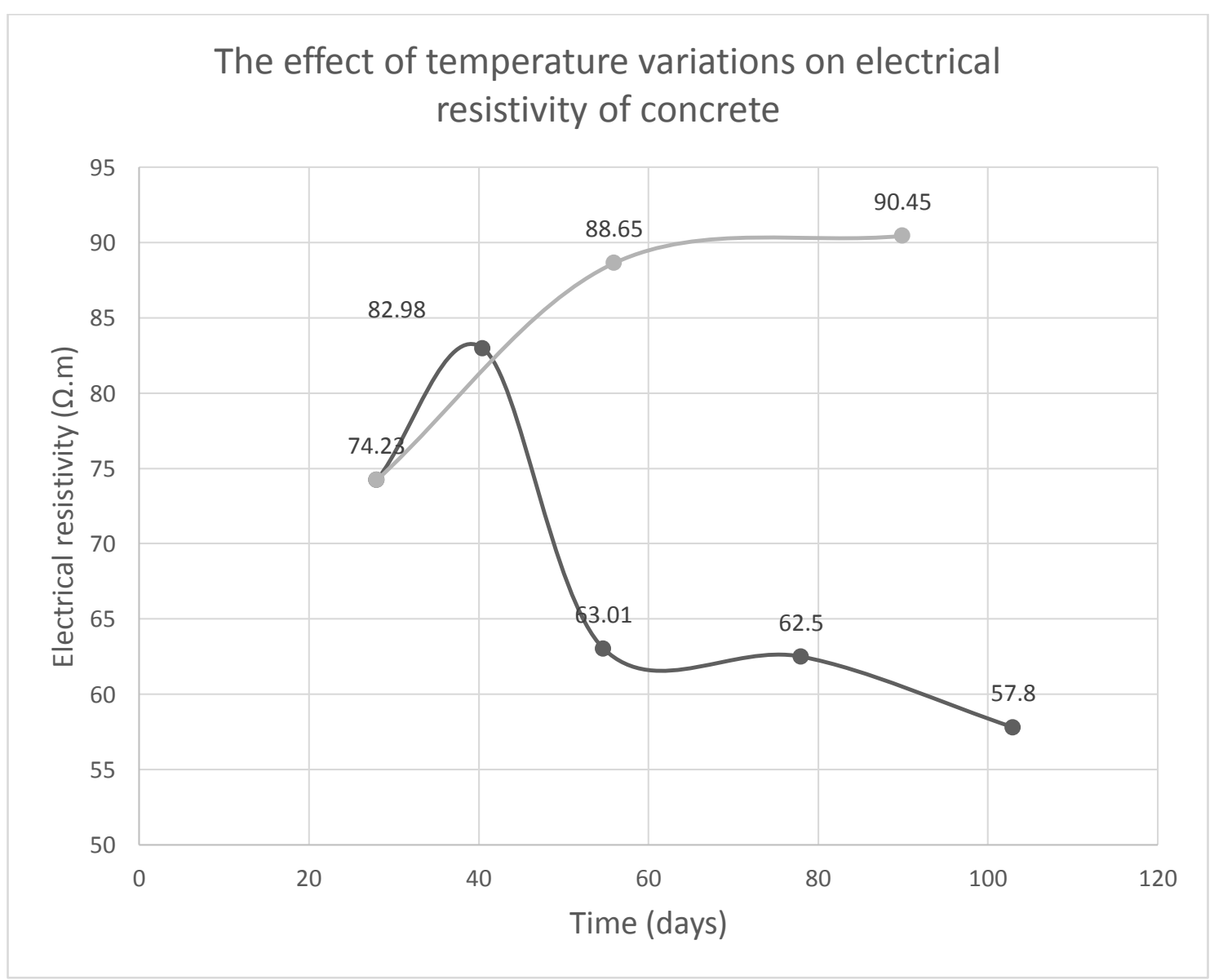

Figure 2:-The evolution of electrical resistivity with: the graph in black represents the evolution of porosity for test specimens having undergone temperature variation cycles and the graph in grey represents sample specimens. 


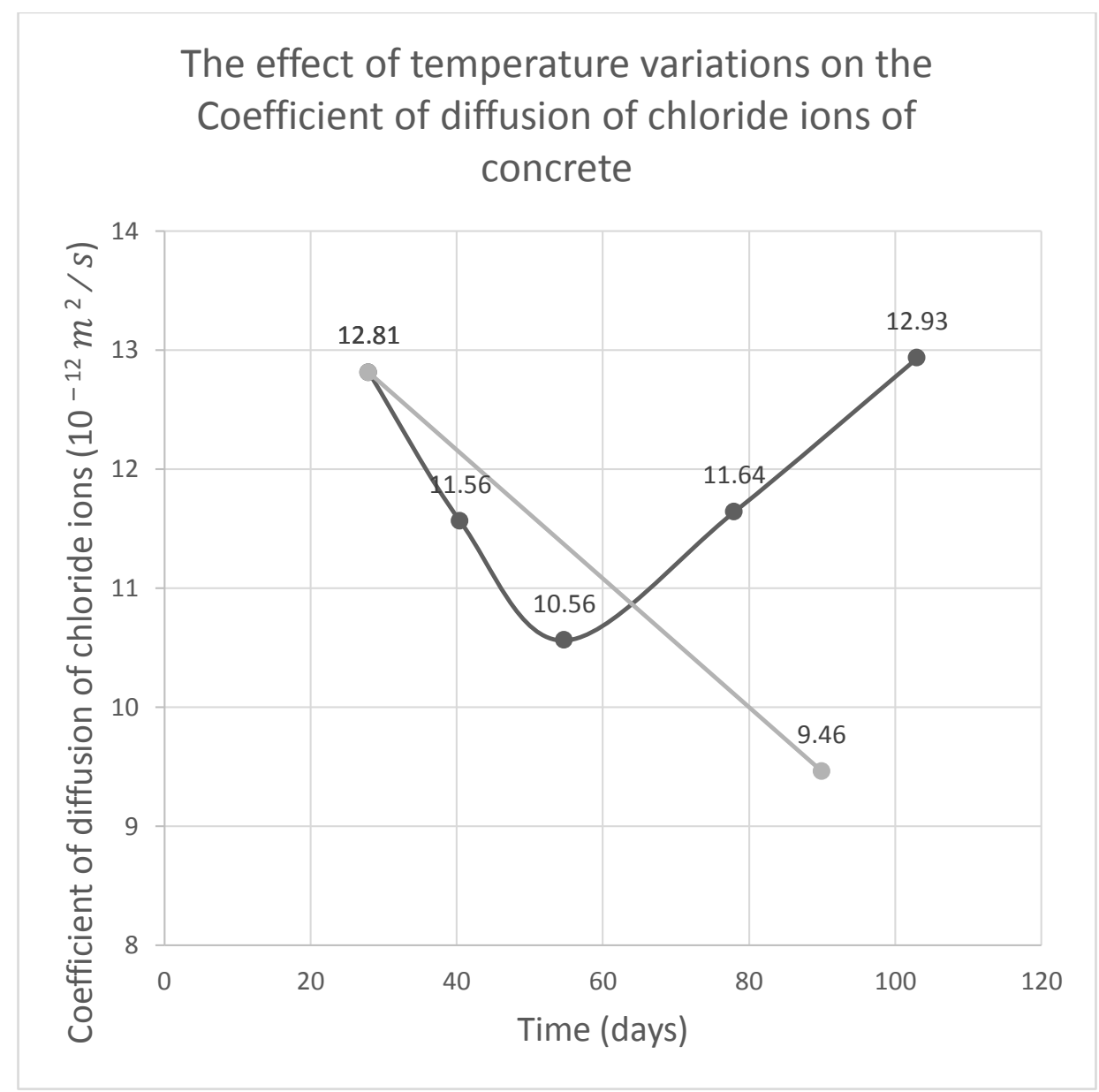

Figure 3:-The evolution of the coefficient of diffusion of chloride ions with: the graph in black represents the evolution of the coefficient of diffusion for test specimens having undergone temperature variation cycles and the graph in grey represents sample specimens.

3. For sample specimens, the potential durability vis-à-vis the gas permeability varies from very low to low according to (AFGC, 2004). While for those subjected to cycles of temperature variation, the durability remains throughout the test very low. In fact, the gas permeability decreases with the number of days for the sample specimens, from a value of $1036.62 * 10^{-18} \mathrm{~m}^{2} / \mathrm{s}$ down to a value of $735.63 * 10^{-18} \mathrm{~m}^{2} / \mathrm{s}$ on the $56^{\text {th }}$ day, so their durability improves. However, the gas permeability of the test specimens having undergone the temperature variation cycles remains stable during the first 50 cycles with a slight decrease from $1036.62 * 10^{-18} \mathrm{~m}^{2} / \mathrm{s}$ to $1032.65 * 10^{-18} \mathrm{~m}^{2} / \mathrm{s}$ then it increases to reach a value of $1853.82 * 10^{-18} \mathrm{~m}^{2} / \mathrm{s}$ at the $107^{\text {th }}$ cycle. We note that for these last specimens, permeability is not affected before 50 cycles, but it increases afterwards. Thus, temperature variation has affected the evolution of gas permeability since the earliest days, but this influence could not be clearly apparent until after 50 cycles. We can attribute the increase in permeability from the 50th cycle to the evolution of the concrete's microstructure with the temperature and especially to the appearance of microcracks that can easily be penetrated by the gas, unlike water. 


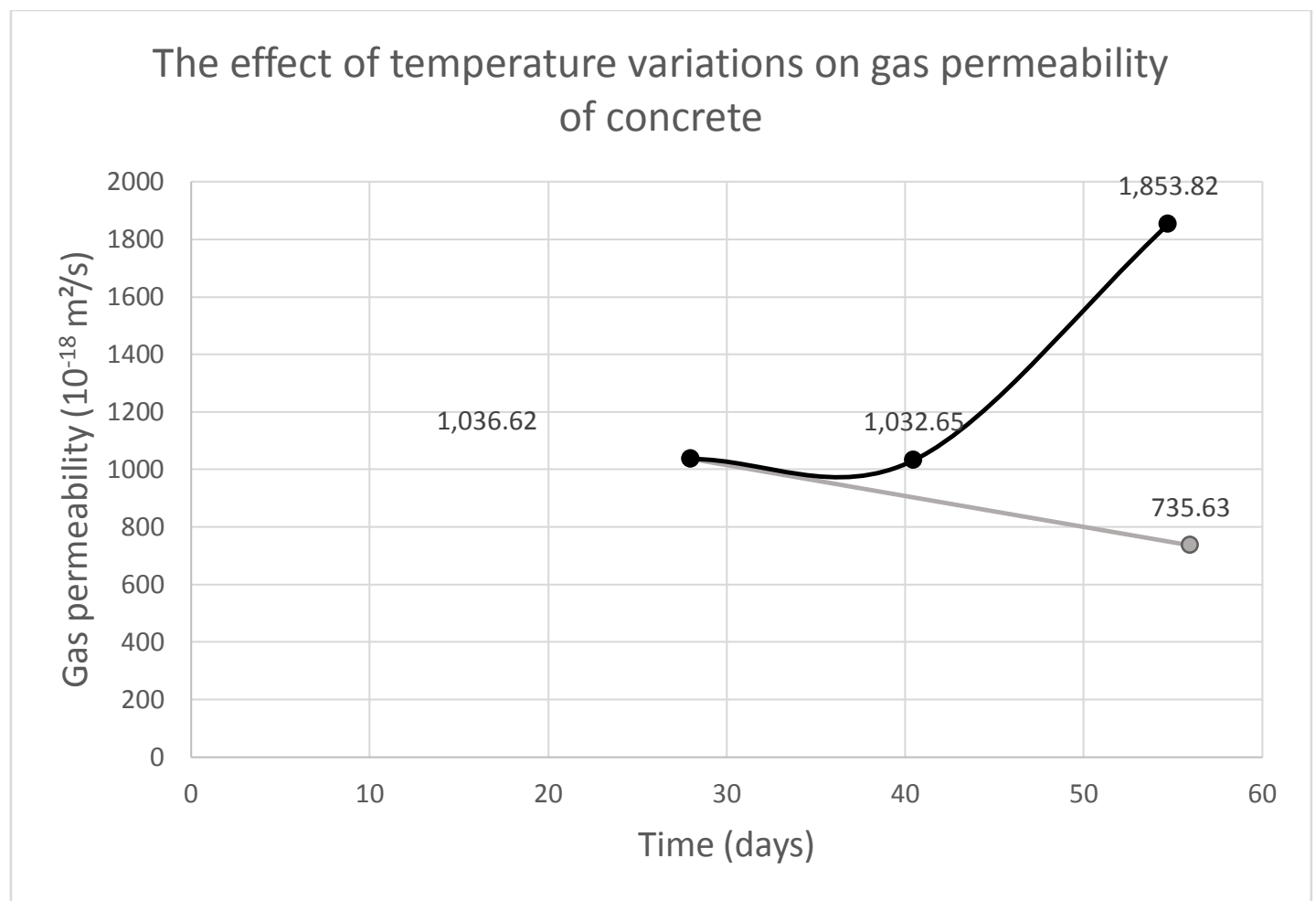

Figure 4:The evolution of gas permeability with: the graph in black represents the evolution of porosity for test specimens having undergone temperature variation cycles and the graph in grey represents sample specimens.

\section{Conclusion:-}

Temperature variations affect all the durability aspects of concrete studied in this paper, namely the porosity to water, the gas permeability, the electrical resistance and the chloride ion diffusion coefficient. However, these effects appear at different stages of the process. In fact, an increase in porosity is apparent after 100 temperature cycles of -5 to $40{ }^{\circ} \mathrm{C}$, whereas the effect of temperature on electrical resistivity and gas permeability is clearly visible after 50 cycles. This could be explained by the fact that the temperature variation impacts the chemistry of the pore water and that the freeze-thaw phenomenon contributes to the appearance of micro cracks which implies the reduction of the electrical resistivity and increase in gas permeability. Furthermore, porosity has not changed much. This can be explained by the fact that the various parameters of the porous network (connectivity as an example) have changed in such a way that the gas permeability increases and the porosity remains intact. Permeability is certainly dependent on porosity, but it is also influenced mainly by the pore connection.

The results have shown that there is a significant effect of ambient temperature adapted to the Moroccan climate on the durability aspects of concrete. Although the range of temperature used is mainly superior to $0^{\circ} \mathrm{C}$, we have found evidence suggesting that the freeze thaw phenomenon occurred and had caused the appearance of micro cracks in the concrete. The effect is not very important especially since we used a relatively durable concrete, usually used in Morocco for structures with a high service life. It can be interesting to conduct the same or similar experiments on other compositions of concrete in order to compare the results. This can be of a good use for decision makers as it will allow them to choose between the different compositions according to various parameters such as the effect of temperature variations.

\section{Acknowledgements:-}

The authors wish to acknowledge the Public Laboratory for Studies and Experiments for putting in our disposition the material, products and resources necessary to conduct the experiments and the Direction of the National Meteorology of Morocco for its assistance in the process of defining the temperature cycle adapted to the Moroccan climate. 


\section{References :-}

1. AFGC. (2004). "Conception des bétons en vue d'une durée de vie donnée des ouvrages - Indicateurs de durabilité. Maîtrise de la durabilité vis-à-vis de la corrosion des armatures et de l'alcali-réaction: Etat de l'art et Guide pour la mise en œuvre d'une approche performantielle et prédictive sur la base d'indicateurs de durabilité. France.

2. AFNOR. (1994). Concrete- Freeze test on hardened concrete - Freeze in water - Thaw in water. P 18-424. Paris, France.

3. AFNOR. (1994). Concrete: Freeze test on hardened concrete. Freeze in Air, Thaw in water. P 18-425. France.

4. AFNOR. (2010, Mars). Béton - Essai pour béton durci - Essai de porosité et de masse volumique. P18-459.

5. AFNOR. (2011, Novembre). Bétons - Essai de perméabilité aux gaz sur béton durci. XP P18-463.

6. ASTM. (2012). Standard Test Method for Field Measurement of Soil Resistivity Using the Wenner FourElectrode Method. ASTM G57-06.

7. ASTM C666 . (2015). ASTM C666 : Standard Test Method for Resistance of Concrete to Rapid Freezing and Thawing. West Conshohocken, PA.

8. Cheng-Yao Zhang, R. H.-M. (2018). Accounting process-related CO2 emissions from global cement production under Shared Socioeconomic Pathways,. Journal of Cleaner Production, Volume 184, 184, Pages 451-465,. doi:https://doi.org/10.1016/j.jclepro.2018.02.284.

9. Gallucci, E. Z. (2006). Influence de la température sur le développement microstructural des bétons. Proceedings of Septième édition des Journées scientifiques du Regroupement francophone pour la recherche et la formation sur le béton.

10. International Finance Corporation, I. f. (2014). Waste Heat Recovery for the Cement Sector: Market and Supplier Analysis. Récupéré sur https://www.ifc.org/wps/wcm/connect/a87be50044581e9889678dc66d9c728b/IFC+Waste+Heat+Recovery+Re port.pdf?MOD=AJPERES

11. Jianda Xin, G. Z. (2018). Effect of temperature history and restraint degree on cracking behavior of early-age concrete. Construction and Building Materials, volume 192, Pages 381-390,.

12. Lagrini K., G. A. (2016). Morocco's freeze thaw map, Contribution to the durability of concrete. Scientific and Technical Journal of Construction(134).

13. Moad Isteita, Y. X. (2017). The effect of temperature variation on chloride penetration in concrete. Construction and Building Materials, Volume 156, Pages 73-82,.

14. NTBUILD-492, N. M. (1999). Concrete, Mortar And Cement-Based Repair Materials: Chloride Migration Coefficient From Non-Steady-State Migration Experiments.

15. Preston, J. L. (2018). Making Concrete Change Innovation in Low-carbon Cement and Concrete. Récupéré sur https://www.chathamhouse.org/sites/default/files/publications/2018-06-13-making-concrete-change-cementlehne-preston-final.pdf. 